\title{
The philosophy of design education at the University of Manchester
}

\section{DOI:}

10.2514/6.2010-9154

Link to publication record in Manchester Research Explorer

\section{Citation for published version (APA):}

Crowther, W., \& Hollingsworth, P. (2010). The philosophy of design education at the University of Manchester. In 10th AIAA Aviation Technology, Integration and Operations Conference 2010, ATIO 2010/10th AIAA Avia. Tech., Int. and Oper. Conf. 2010, ATIO 2010 (Vol. 2). American Institute of Aeronautics and Astronautics . https://doi.org/10.2514/6.2010-9154

\section{Published in:}

10th AIAA Aviation Technology, Integration and Operations Conference 2010, ATIO 2010|10th AIAA Avia. Tech., Int. and Oper. Conf. 2010, ATIO 2010

\section{Citing this paper}

Please note that where the full-text provided on Manchester Research Explorer is the Author Accepted Manuscript or Proof version this may differ from the final Published version. If citing, it is advised that you check and use the publisher's definitive version.

\section{General rights}

Copyright and moral rights for the publications made accessible in the Research Explorer are retained by the authors and/or other copyright owners and it is a condition of accessing publications that users recognise and abide by the legal requirements associated with these rights.

\section{Takedown policy}

If you believe that this document breaches copyright please refer to the University of Manchester's Takedown Procedures [http://man.ac.uk/04Y6Bo] or contact uml.scholarlycommunications@manchester.ac.uk providing relevant details, so we can investigate your claim.

\section{OPEN ACCESS}




\title{
The Philosophy of Design Education at the University of Manchester
}

\author{
Peter Hollingsworth* and William Crowther ${ }^{\dagger}$ \\ The University of Manchester, Manchester, M13 9PL, UK
}

\begin{abstract}
The University of Manchester was created in 2004 through the merger of the Victoria University of Manchester (VUM) and the University of Manchester Institute of Science \& Technology (UMIST). Both of the constituent universities had an undergraduate aerospace engineering program. The combination of the two undergraduate programs along with the development and initiation of a post-graduate Master of Science program required a reassessment of the design units at the university. As such the current aerospace engineering curriculum has evolved and is continuing to evolve from those of it predecessors and the development and inclusion of new course material. This evolution has included a restructuring of unit contents, an increased focus on defending design decisions and the breadth of the systems design process. The changes to date have focused on the 3rd and 4th years of the BEng and MEng programs respectively and the inclusion of MSc students. Future work will incorporate changes to the 1st and 2nd years along with further changes to the existing units.
\end{abstract}

\section{Introduction}

The current design program, for undergraduate aerospace engineering students, is structured to meet the UK Standards for Professional Engineering Competence (UK-SPEC) ${ }^{1,2}$ and as such the design program and philosophy have been developed, and are continuing to be developed, with this in mind. Since the undergraduate engineering program consists of two basic degrees, the three year Bachelor of Engineering (BEng) and the four year Master of Engineering (MEng), it is necessary to create a design program that produces competent engineers after their third year of study. Consequently, the program has four primary design units, plus a set of units that focus on Aircraft and Aerospace Systems. The units, except for the first year design, are coordinated to provide an escalating knowledge of aircraft performance, systems, and design. The first year unit is based around a common module for Aerospace, Mechanical and Civil engineering students with case-studies and practical work geared toward the individual courses. The year 2 design unit links lectures with a relatively straight-forward project designing a commercial jet transport. Students perform the work either individually or in small groups of three max. The third and fourth year design units are primarily project based, structured in teams of five or six. The third year unit currently has a small number of seminar lectures that are geared toward the requirements of the design project.

\section{Current Design Projects}

The current projects, as described here-in, focus on the third and fourth/MSc years of study in the aerospace engineering program, as these modules are the focus of recent and ongoing work to improve the material being taught, the delivery methods, and the student outcomes. Currently, the first and second year design units are not being revisited as they provide a reasonable basis for the future activities of the student body.

*Lecturer, School of MACE, Sackville Street, Manchester, UK, peter.hollingsworth@manchester.ac.uk, AIAA Member

†Senior Lecturer, School of MACE, Sackville Street, Manchester, UK, bill.crowther@manchester.ac.uk 


\section{II.A. Third Year Design}

The 2010 third year design unit is run as a single term, in this case the spring term, module worth 10 credits. This leads to an expectation that students will spend approximately 100 hours over the course of the term sitting in lectures, working on projects and revising. The project is structured as the preliminary design of either a UK microlite aircraft ${ }^{3}$ or a EASA very light aircraft (CS-VLA). ${ }^{4}$

Each of the students that undertook the design course had had a single semester of basic aerospace vehicle design in their second year, plus aircraft flight performance. The second year design course focused on a fairly rigid design of a civil transport aircraft. As such the students had been introduced to the concept of point performance analysis and basic aircraft sizing and synthesis. However, they had not been forced to reflect upon how these methods were arrived at. This basis would prove to be one of the issues with the approach undertaken for the Design 3 unit, as discussed below.

Because of the fact that the students had a background in sizing and aircraft performance, it was decided that the project scope, be it either the the microlite or CS-VLA, should be more open ended than would typically be the case for an undergraduate design. In this case the students were required to digest and understand the relevant regulations and meet what the design teams determined the market demanded.

\section{II.A.1. Brief}

Working in groups of 5 or 6 , develop a conceptual and preliminary design for either a UK microlight or a EU CS-VLA aircraft. Each team was assigned a slightly different starting point to . The goal was to meet the performance and market requirements and develop a certification plan. The aircraft was to be designed to meet the airworthiness requirements contained either in UK CAA CAP $482^{3}$ or EU CS-VLA. ${ }^{4}$

\section{II.A.2. Design Task}

The design task as set-out covers two primary phases with a critical review in the middle. The basic contents of each phase are given below.

\section{Stage 1: Basic Sizing and Plan Development}

- Digest appropriate regulatory documents

- Select basic configuration where applicable

- Work out design take off weight and basic weight breakdown (empty, fuel, payload)

- Construct basic payload range diagram

- Determine Thrust to Weight ratio and Wing Loading from a constraints analysis

- Determine wing area

- Select engine and propeller (note: they do not have to currently be certified, but propulsions systems certification will then need to be accounted for)

\section{Stage 2 Configuration Detail}

- Define Seating arrangements

- Layout Instruments and Controls

- Define wing, stabilizer, and control surface geometry

- Determine static and dynamic stability, including derivatives

- Develop plan to assess and computationally asses performance to applicable documents

- Create certification plan

Handling qualities must be simulated and tested in a flight simulator

A Minimum of 10 certification requirements (including handling qualities must be computed) 
While the first stage of the design process is relatively standard, performing a high-level conceptual design, it is up to the students to determine the market requirements and digest the intricacies of the regulatory documents. Support is provided for each team digesting and understanding the different language in the UK and EASA specifications.

\section{II.A.3. Assessment}

The students are assessed, as a group, on five different occasions. The first occasion is a short, five minute presentation, during the second week of term. A report is due a week later followed by and interim progress report at mid-term and a final report and presentation at the end of the term.

Preliminary Presentation A Group presentation, in Week 2, addressing team organization and how each group plans to address the technical challenges. The presentation will be limited to $5 \mathrm{~min}+5 \mathrm{~min}$ of questions. Each group will prepare a single side of A4 paper with key points on their ideas. These will be handed out at the start of each presentation. Feedback is provided both during the presentation and in written form by the instructor. This feedback includes both individual and class wide comments.

Preliminary Plan Report A six page group report based upon feedback from preliminary presentation. This includes work plan, programmatic risk assessment, timeline and certification goals. This will also include an initial list which certification requirements will be tested in the simulator, and which will be computed. Additionally material can be provided in the report appendices beyond the six pages. Feedback is provided in written form within a week of submission.

Interim Report A 15 page group technical report on Stage 1, including figures and illustrations. The objective of this document is to communicate the initial results of Stage 1 tasks and any changes to the work plan presented in the Preliminary Report. Includes engine and propeller selection, basic configuration and general weights and aircraft performance. Again feedback is provided by the instructor within one week of submission.

Final Presentation A final group presentation of your design to a non specialist aerospace audience. Specific presentations materials can include electronic slides, posters, briefing notes, and other materials as deemed appropriate. Be as creative as you can in presenting a visually engaging and informative description of your design. Include key facts and figures lifted from your final report where appropriate. Provide a list of credits identifying the main contributions of the team members. The presentation is assessed $100 \%$ on presentation and the ability to answer technical and programmatic questions. The presentations take place during the second to last week of the academic term, over the course of a single day.

Final Report A final group report on the final aircraft configuration and status. This includes the certification plan. The objective of this document is to communicate the current status of the design including all Stage 1 and Stage 2 elements. The report is 20 pages in length for the main text, not including appendices. Required appendices include, Appendix A: Certification plan and simulations status. This must list all of the certification requirements that are contained in the respective regulatory documents and current status and future plan for certification. The report should include detailed results for the 10 requirements and high level overview for other requirements. Further appendices may include additional information such as any reduction of data and multivariate sensitivity analyses. This report is submitted in the final week of the academic term.

\section{II.A.4. Outcome of the Design Effort}

The third year design results were somewhat disappointing, though not unexpected considering the knowledge base and previous experience in the second year design and other course modules. The students initially struggled with how to approach an open ended problem. Specifically with the task set for the initial presentation. Further, as most students are apt to do, they often fell back upon what work they had done in the past without thinking about whether or not such an approach was the correct one for the problem at hand. In the end the students were capable of producing final, closed design cases, with some level of detail. Furthermore, there was enough variety in the range of designs that worries about having too much similarity between the difference groups proved to be unfounded. 
Each of the design teams was able to produce a single design of varying detail, that fit the needs and regulations of their respective market and certifying authority. Two examples of these designs are given in Figure $1^{\mathrm{a}}$.

Some general comments about the results of the module as it pertained this year include:

- There needs to be a greater focus in the distillation of the RFP/Project description into aircraft performance specifications.

- Continuing support in aircraft performance, both point and mission, needs to be provided. Previous, unit work seems to have been forgotten

- Open ended design problems need significantly more contact time than the single semester design unit provided. This was particularly true for new concepts and material which needed further time for introduction

- The simulation requirement was too open ended and ill-defined.

- The highly coupled feedback loop, with significant interim deliverables was successful in improving the final design work.

These comments and outcomes have been taken into account in the module revisions that are being incorporated into the revised design unit described in a later section.

\section{II.B. Advanced Design (Fourth Year)}

The fourth year design unit is run as a full year 30 credit module. There are two reasons for the increase in both credits and contact time with the students. The first has to do with the increase in specialization that is the focus of the fourth year of the integrated MEng program. The second is that many of the fourth year modules, Advanced Aerospace Design included, are shared with the departments Master of Science (MSc) program, which is based upon an even greater focus and specificity. This sharing of units between an undergraduate masters program and a post-graduate masters program creates some unique challenges and opportunities for the Advanced Aerospace design module.

The goal of the fourth year project is to develop a parametric design process, create a design, build, test, and update the process. The environment would allow for the design and production of fixed wing UAVs for autonomous flight vehicle training applications. In other words, instead of creating a design and building and associated vehicle, the students were asked to develop a parametric process and test and evaluate the process. This testing and evaluation would first be done by using the process to develop several single point designs, and second by building and testing one of these designs.

\section{II.B.1. Specific Requirements}

The specific task requirements for the project included:

- The input to the design process will be a customer requirement defined by a combination of payload mass, flight duration, max climb angle, manoeuvreability and operational weather conditions. The approximate limits of the required design envelope are an all up flight mass of less than $1.5 \mathrm{~kg}$, maximum flight speed less than $15 \mathrm{~m} / \mathrm{s}$, duration less than 1 hour, max climb angle less than $45 \mathrm{o}$. Groups will be provided with group-specific design points after the preliminary design review

- The vehicle payload is to be a VGA quality or better video camera with minimum $100 \mathrm{~m}$ line of sight wireless transmitter. The ability to store video onboard would also be an advantage

- The vehicle should be equipped with the Paparazzi autopilot system (approximately mass 70g). Flight testing will be in manual control mode (mode 1)

- It is desirable that the vehicle can be test flown in a minimum weight configuration without autopilot and camera

\footnotetext{
${ }^{a}$ Courtesy of Sam Burt, James Chard, Zachary Chau, Sanket Bansal, Hunlign Bekele, Mohammed Bhatti and Ben Rajan, Samuel Ratcliffe, Alex Proctor, Tilemahos Rodis, Abofazl Salarian Zadeh, Deepthi Shanmugasundaram
} 


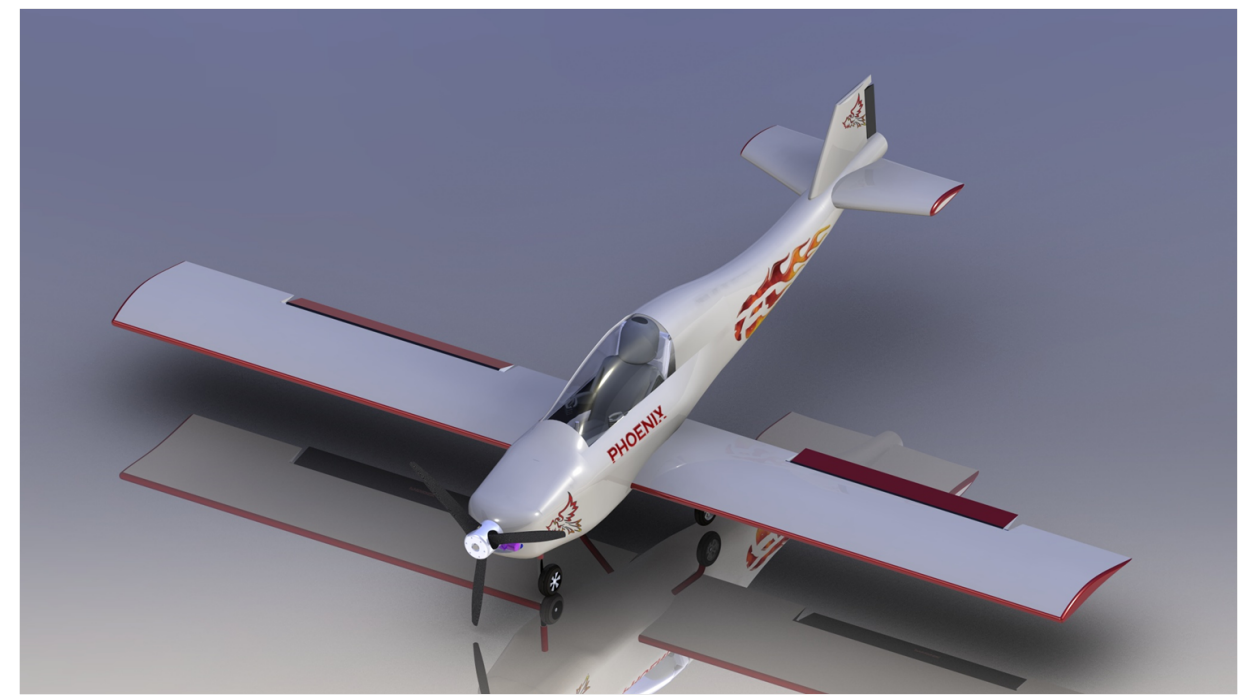

(a) EASA CS-VLA Design

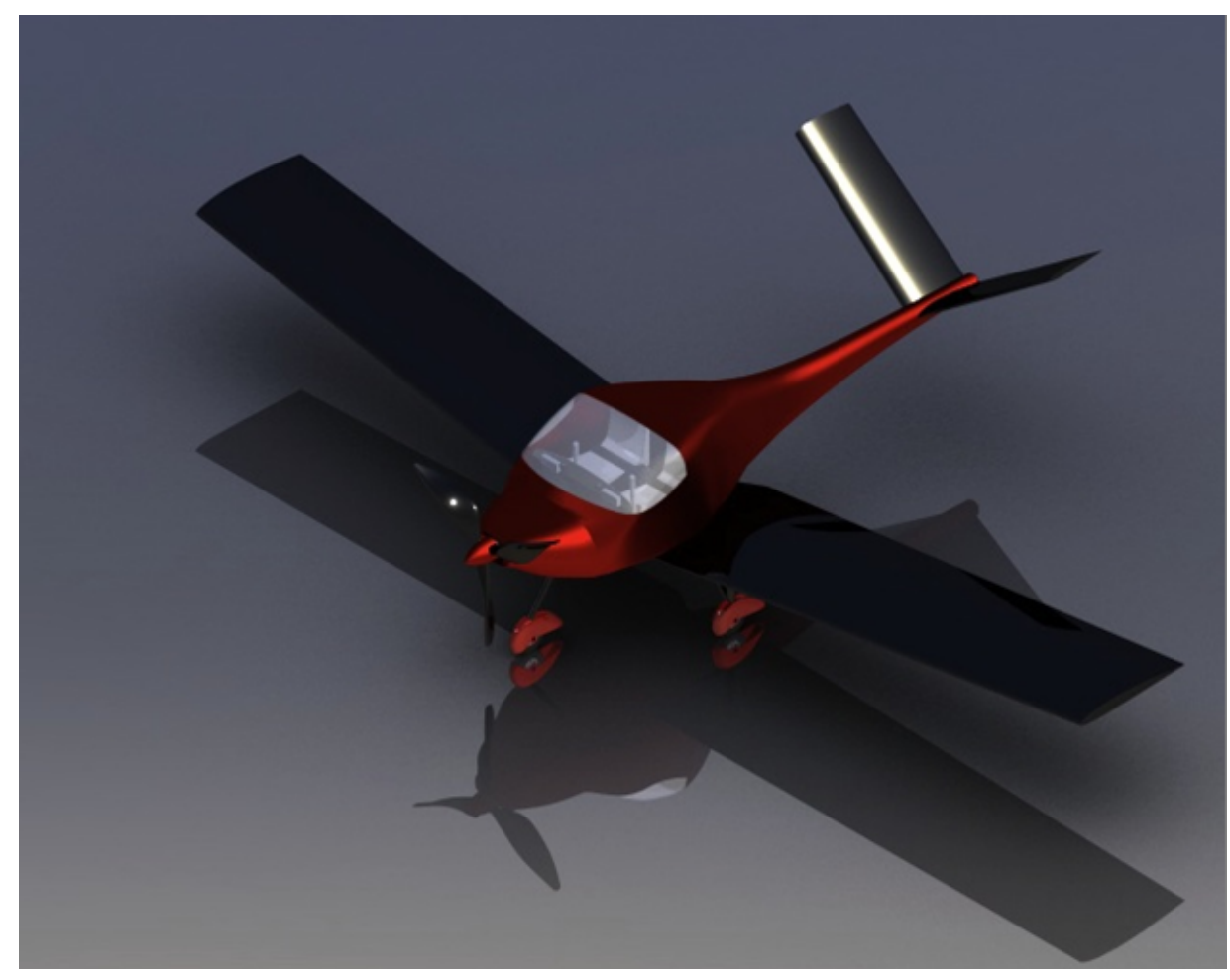

(b) UK CAA Microlight Design

Figure 1. Sample of Student Small Aircraft Designs, Design 3 
- Propulsion power source should be electric

- The vehicle should be easy to fly by a novice model RC pilot

- The airframe must be robust to hard landings and easily repairable following a crash. The flight control hardware and propulsion system must be protected from crash damage as far as practicable

- Airframe components should be COTS or manufacturable within a university workshop environment using rapid manufacturing techniques suitable for undergraduate students, e.g. foam hotwire, plastic vacuum forming, basic metal working using hand tools. Hot wire foam cutting of wing sections will be outsourced, outsourced laser cutting of 2D parts will also be available.

- The airframe, RC system (receiver, servos) and propulsion system (battery, motor, speed controller, prop) cost should be as low as practicable and must be less than 200 including labor costs (cost will depend significantly on vehicle specification). Cost of camera payload and autonomous systems hardware should be evaluated separately.

- A Simulink-based flight simulation should be provided to support flight training and evaluation of autonomous operation of the vehicle

- Design calculations must be backed up with test data from experiments wherever practicable

\section{II.B.2. Assessments}

The project had a series of group and individual assessments. These included:

- Project Bid Document - A bid to start the project. The proposed work-plan is assessed along with the organisation and project goals

- Preliminary Design Review Presentation - A review of the preliminary design of the 'design process'. The purpose of this review is to ensure that the processes that are developed will be capable of meeting the actual UAV design task that is assigned to the groups. Immediately after this assessment each group was given a more specific region of the design space in which to exercise their process and design an aircraft.

- Final Design Process Report - A report showing the completed process, it includes evidence of the capability of the report, plus the preliminary design of the test aircraft that will be constructed. This report is assessed on both a group basis and individually.

- Trade Show - Aimed to allow the groups to sell their design process and specific design to potential customers through the medium of a presentation stand similar to those typically found a trade fairs. Potential 'customers' will spend no more than 5 minutes at any one stand. Material is presented in the form of posters, table top hardware/models, CAD model or equivalent on a laptop, and a flight simulator.

- Video Demo - A short (5 minute max) video presentation illustrating your design method and example vehicle. The video content is supposed to be engaging for a non technical audience but also deliver the key technical messages to potential customers. The video should be an advert for the capabilities of the team, not a product sales pitch. It is assessed on a group basis based upon the ability to communicate the key ideas.

- Reflective Log \& Interview - A written log and subsequent interview in which the students review the learning experience across the module, especially with relation to how their knowledge and key engineering expertise has increase, their contribution to the team, and at least one area for further professional development. The report and interview are assessed solely on an individual basis. 


\section{II.B.3. Outcome of Advance Aerospace Design}

The goal of having the student design groups focus not just on a single design but the relationship between design, its parametrics and issues with manufacturing and testing was a general success. However, as with any unit that is attempted for the first time this was only partially successful. Several issues arose that delayed both the development of the parametric process and the ultimate build and test phase.

The first major issue centered on the students comprehension of the task that was set out. Most of the students focused, initially, on designing a single UAS that they could build and test. This is because none of the students had been formally introduced to the concept of a parametric design space in any of their earlier work, let alone how to develop a full design process and environment. This was further compounded by the fact that a significant number of the students, those on the MSc course, did not have aerospace backgrounds.

This past year teams were split up based upon which degree course, MEng or MSc, the students were registered. However, a couple of the MSc students were accommodated within the MEng groups. The outcome of this is that while the MEng groups got stuck trying to figure out the difference between a single aircraft design and a design process, the MSc groups often struggled with the whole process of designing any sort of aircraft. The outcome of this is that the MSc students assigned to the MEng groups performed better and viewed their experience as superior to those in MSc only groups.

The second major issue concerned the timeframe for the manufacture, construction, and testing of the demonstration designs. Due to the delays in the development of the design process, mentioned above, the initial orders for externally sourced components were delayed into 2010. With some of these components having rather long lead times, specifically the externally sourced wings, this delayed the initial construction and testing. The result of this was that the actual flight testing was delayed until very late in the Spring 2010 semester, effectively too late to allow for an update to the design process to be performed.

Nevertheless, several of the design process were capable of producing a range of different designs to meet different specifications for different performance metrics. These are shown in Figure $2^{\mathrm{b}}$ and Figure $3^{\mathrm{c}}$.

\section{Developments and Changes for 2010-2011 Academic Year}

Last year's design efforts were the first iteration of the rework of the undergraduate aerospace design program at Manchester. As a consequence of the lessons learned during the 3rd year design exercise significant changes are being made to the unit, while more minor tweaks are being implemented for the 4th year Advance Aerospace Design.

\section{III.A. Aerospace Design 3 Rework}

The biggest change in the approach to the third year aerospace design course is the incorporation of the material from the school's old Aerospace Systems II unit. This unit, which focused primarily on aviaionics and subsystems, had become somewhat disconnected from the current curriculum. However, there are still several topics that were included in this unit's syllibus that are pertinent to the design of aerospace systems. As such the two units have been combined into a single, two-semester 20 credit module. This provides an opportunity to restructure the delivery of content to better meet the learning needs of the students. In this case it is possible to introduce new concepts when they are most applicable, e.g. focus on the electrical subsystem when the more detailed design aspects are relevant instead of three to four months prior. This seems to increase the likelihood that students will learn and remember those topic areas.

An additional benefit is that the design project can now be made a year long, with significant opportunities for review and redirection as necessary. This means that the project is no longer governed solely by the need to complete it in a 12 week time period. Instead with 24 weeks available it is possible to look at a broader range of concepts and design and decision points.

The revised project structure will touch on everything from requirements analysis, to system-of-systems interaction and operations, to the actual vehicle and subsystem design. The levels of detail associated with each will be commensurate with both the time available and the level of student. At the time of writing the project structure for the upcoming academic year was still being finalized.

\footnotetext{
${ }^{\mathrm{b} C o u r t e s y}$ of Haris Iftikhar, Ciaran McAndrew, Pawan Hurnath, Orestis Gerogiades, William Jones, Kang Kian, Eberechukwu Okwor, Adam Pottinger, Sinduja Rajan Babu, George Sandford, Aaron Sigger, Christopher Smith, and James Stephenson

${ }^{\mathrm{c}}$ Courtesy of Aaron Sigger
} 


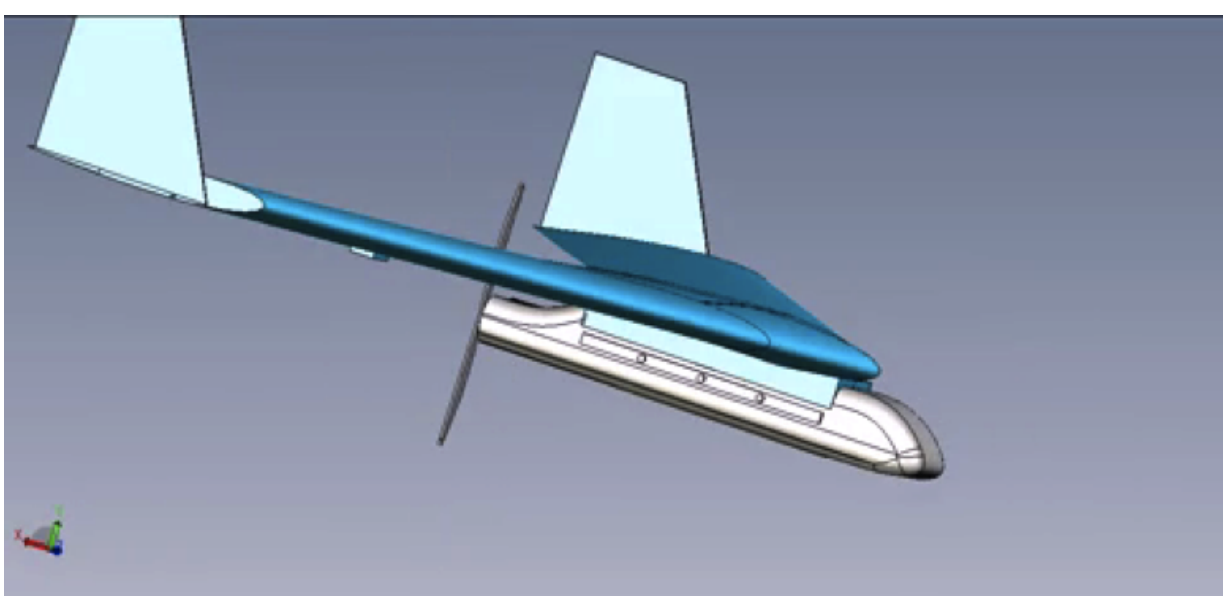

(a) Flying Wing Design Output

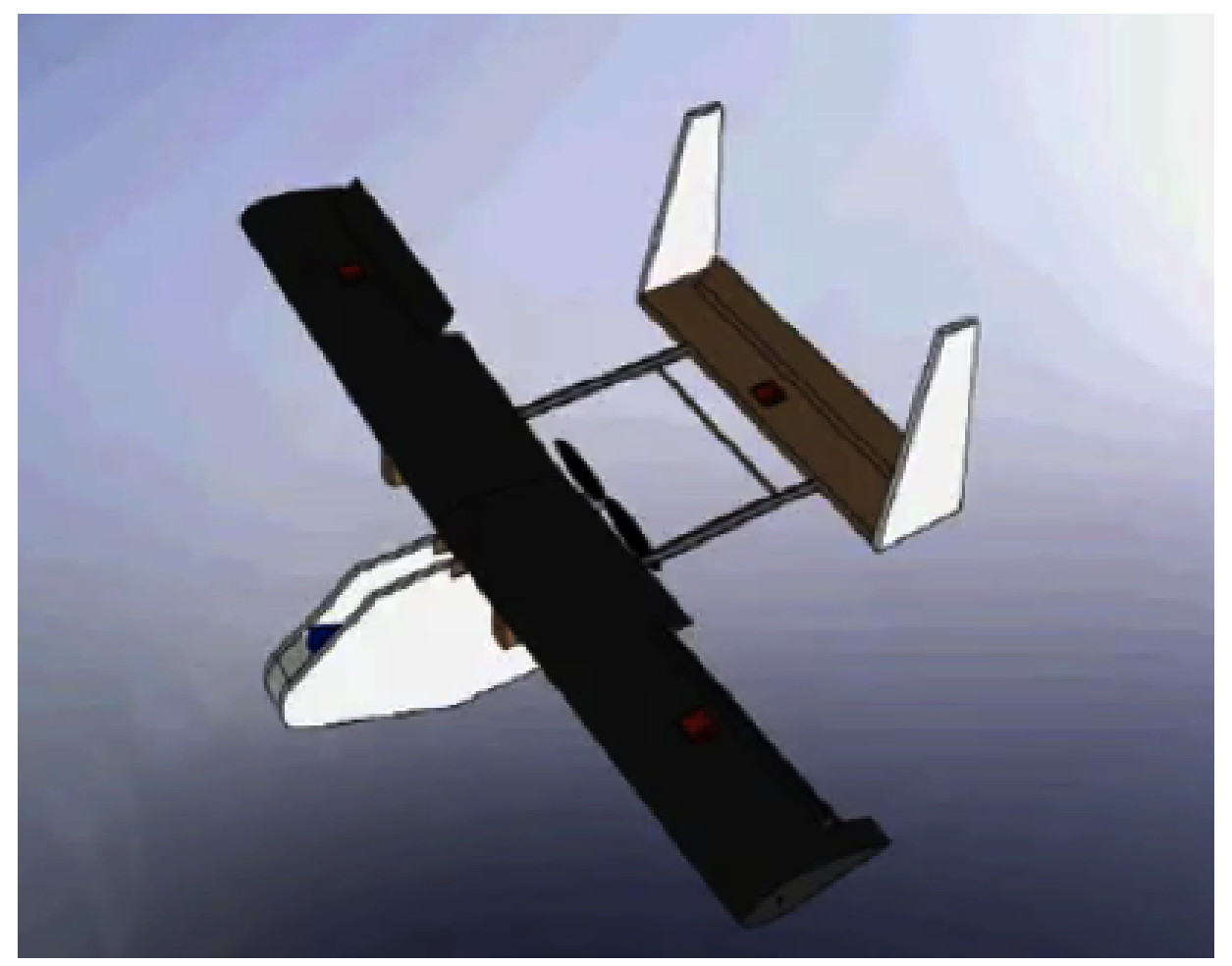

(b) Twin-boom Design Output

Figure 2. Sample of Design Process UAVs, Advanced Aerospace Design 


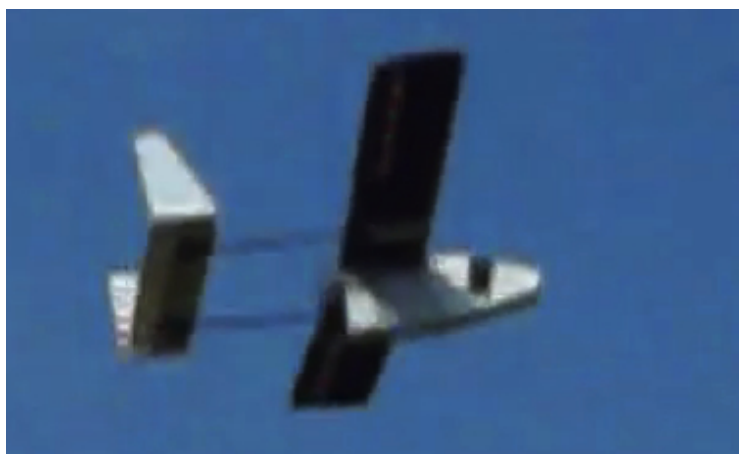

Figure 3. Twin-boom Design in Flight

Another, benefit of the increase time-line for the third year design unit is the ability to expand the avenues of feedback. Taking from the practices of Advanced Aerospace Design, both group and individual feedback and marking is to be provided. This overcomes the possibility that a team member does not contribute but still manages to obtain a satisfactory grade/mark.

Since this is a wholesale restructuring of the third year design unit, effectively meaning that the previous unit was a one off placeholder, further modifications are anticipated, especially in light of the deficiencies that have been identified amongst the Advanced Aerospace Design cohorts.

\section{III.B. Advanced Aerospace Design Modifications}

As mentioned, the modifactions to the Advanced Aerospace Design module are significantly less intense. Two primary changes are being made, the first is to incorporate the MSc students into grouped with MEng students, the second to bring forward a design-build-test exercise into the first two weeks of the course. Additionally, the structure of testing phase of the process verification is being made more rigorous to ensure that the static and flight testing is truly value added.

As mentioned in previous sections the MSc students that were placed within MEng groups both performed better and reported a better experience. This coupled with the fact that the ratio of MSc to MEng students is anticipated to increase necessitated a revisit to the assumption that the MSc students would be less likely to be "left behind" if they were grouped together. This is especially true when a substantial portion of the MSc students do not have aerospace backgrounds. In such a case it is essential that these students be paired with aerospace students who are familiar with the University of Manchester culture. It is hoped that this when combined with the initial design-build-test exercise will help alleviate the problem of teams having trouble with the aircraft sizing and synthesis aspect of the design process development.

In addition to the aircraft sizing and synthesis issues that were identified with the MSc students, it was obvious that very few of the students have much if any small UAV or model aircraft building experience. As such a simple hand launched foam glider design-build-test exercise is being incorporated into the first few weeks of the upcoming term. This is designed to be an intensive experience to instill a comprehension of the issues involved with taking an aircraft design from the paper to the foam phase and the testing involved. The purpose of this is to help link the development and use of the UAV design process to the testing that will be performed in the spring semester. The feedback associated with this effort will prepare the students for the new requirements that will be imposed on the final testing portion of the project.

The changes to the static and flight testing portion of the project are based upon the need to feedback the knowledge gained from building and testing articles into the design process. As such the test stages are to be made more rigorous. The teams will have to submit test plans, implement these plans, and reflect on the outcome of the tests. Where time allows modifications to the plans and/or the aircraft will be made and further tests will be carried out. The key to this is to shorten the lead time for the aircraft components. In order to accomplish this it is anticipated that the fabrication of the key structural components will be brought in house. It may not be practical to fully implement this in the coming academic year, but it is anticipated that this will be done over the next several years. 


\section{Future Changes}

While the changes to the fourth year Advanced Aerospace design are relatively minor. They coupled with the more radical rework of the third year design unit and exercise set the ground-work for a revisit of the entire design and systems curriculum at the university. It is anticipated that the first and second year design and systems courses will be revisited in upcoming academic cycles in order to provide a continuous means of improving student outcome. One of the advantages of having multiple design units spread throughout the aerospace course is that it makes it possible to introduce concepts that re-enforce the theoretical learning either simultaneous to or shortly after those subjects have been covered in their fundamental modules. It is anticipated that future design exercises will make use of this advantage, all while building to the final year (years three and four) design exercises.

Additionally, the university's engagement with the local aerospace community, specifically engagement at the educational level, suffered during the merger. The Northwest of England and North Wales has a relatively dense concentration of aerospace capability. This if further augmented with a broader industrial community in the remainder of England, Great Britain, and the United Kingdom as a whole. Starting in the 2010-2011 academic year a re-engagement of the community is planned. This will focus on recapturing the expertise of practitioners in the design revue process and ultimately in the development of the design tasks. Taking into account both the needs and interests of industry, plus the educational and continuity requirements of the undergraduate and post-graduate programs.

\section{References}

1 "UK Standard for Professional Engineering Competence," Standard, Engineering Council UK, London, UK, 2010.

2 "The Accreditation of Higher Education Programmes," Specification, Engineering Council UK, London, UK, 2010.

3 "British Airworthiness Requirements: Section S - Small Light Aeroplanes," Regulation CAP 482, Civil Aviaiton Authority, 21 October 2009 [cited 1 Septembr 2010].

4 "Certification Specifications for Very Light Aircraft," Specification CS-VLA, European Aviation Safety Agency, 05 March 2009 [cited 1 Septembr 2010]. 